\title{
UNIDADE FISIOGRÁFICAS DE RELEVO DA BACIA HIDROGRÁFICA DO RIO ITU - OESTE DO RIO GRANDE DO SUL
}

\author{
Romario Trentin $^{(a)}$, Luís Eduardo de Souza Robaina ${ }^{(b)}$, Rhael David Lara Partida ${ }^{(\mathrm{c})}$, Maria José \\ Entrena Pineda ${ }^{(\mathrm{d})}$
}

(a) Departamento de Geociências/ Universidade Federal de Santa Maria, romario.trentin@gmail.com

(b) Departamento de Geociências/ Universidade Federal de Santa Maria, lesrobaina@yahoo.com.br

(c) Departamento de Geociências/ Universidade Federal de Santa Maria, rhael.lara5@gmail.com

(d) Departamento de Geociências/ Universidade Federal de Santa Maria, mariajoseentrena@gmail.com

\section{Eixo: GEOTECNOLOGIAS E MODELAGEM ESPACIAL EM GEOGRAFIA FÍSICA}

\begin{abstract}
Resumo
O trabalho tem com objetivo estabelecer a compartimentação fisiográfica da bacia hidrográfica do Rio Itu. Utilizou-se além de parâmetros de relevo, atributos litológicos e de solos combinados em SIG. Os dados de elevação foram discriminados em duas classes, sendo elas maiores e menores de 186 metros. As informações de declividades foram discriminadas em duas classes, sendo elas maiores e menores que $15 \%$. Por fim, os solos foram discriminados em três classes: solos hidromórficos, solos rasos e solos profundos. O cruzamento automático definiu 24 unidades, sendo que, as unidades que não representavam espacialmente a configuração de uma unidade fisiográfica, foram reagrupadas em unidades com características semelhantes, o que condicionou a delimitação de 15 unidades fisiográficas para a bacia hidrográfica do Rio Itu. Destas unidades fisiográficas, seis são grandes unidades espaciais que representam o predomínio das áreas da bacia hidrográficas, e as demais unidades, apesar de ocuparem pequenas áreas representam situações especificas da área de estudo.
\end{abstract}

Palavras chave: Relevo, Fisografia, Bacia Hidrográfica

\section{Introdução}

O comportamento natural de uma bacia hidrográfica, está diretamente relacionada às características dos elementos que à compõem. Entender o comportamento desta, demanda a análise integrada dos elementos de modo a estabelecer a interação das variáveis possibilitando o conhecimento do sistema, o que dará suporte ao embasamento de estratégias de planejamentos e tomadas de decisões.

O presente trabalho apresenta como objetivo, estabelecer uma compartimentação fisiográfica do relevo, através de cruzamentos em SIG, da bacia hidrográfica do Rio Itu. O meio físico deve ser analisado com base nos "landforms", entendidos como os elementos do meio que possuem composição litológica e variações das características visuais e físicas definidas, tais como: forma topográfica, modelo de drenagem e morfologia (BELCHER, 1946, apud ZUQUETTE, 1993).

A proposta de classificação segue a fundamentação dos geossistemas (Sistema Geográfico ou Complexo Natural Territorial), proposto inicialmente por Sotchava, na década de 1960, que propõem o estudo da 
dinâmica e estrutura das paisagens pelo viés sistêmico, através da delimitação e hierarquização de características homogêneas (TROPPMAIR, 2004).

Freitas e Cunha, (2004) abordando sobre a compartimentação espacial através da visão geossistêmica apontam que este método estabelece critérios que buscam a identificação e agrupamento do comportamento das variáveis ambientais, destacando os processos morfodinâmicos da paisagem de origem natural (geologia, geomorfologia, clima, hidrologia e ecossistemas) e antrópica (baseada na ocupação sócio histórica).

Vários são os pesquisadores que definem a bacia hidrográfica como unidade ideal de planejamento ambiental, por ser uma unidade natural de análise da superfície terrestre, onde é possível identificar e caracterizar as relações entre os vários elementos que constituem esta unidade. A bacia hidrográfica é comumente associada a um sistema físico aberto, em que há a atuação de processos naturais ou antrópicos no ambiente, e como respostas podem ser observadas mudanças no meio físico. Essas modificações resultam da busca do equilíbrio dinâmico (CHORLEY; SCHUMM; SUGDEN, 1984); (CUNHA; GUERRA, 1996).

Para (PIRES, 2000), a opção de trabalhar com a bacia hidrográfica, como unidade de análise, permite introduzir um aspecto na conceituação que é o planejamento integrado com a comunidade envolvida, ou seja, trabalhar a relação homem/natureza no dia-a-dia de cada cidadão.

Recentemente, com o desenvolvimento de métodos de geoprocessamento e SIGs é possível a representação da superfície terrestre na forma de modelos digitais numéricos, denominado também de Modelos Digitais do Terreno (MDT), os quais possibilitam a análise topográfica de uma zona de interesse, assim como o cálculo automatizado de uma série de variáveis relacionadas (VIDAL-TORRADO; LEPSCH; CASTRO, 2005).

Neste trabalho utilizou-se além de parâmetros de relevo, atributos litológicos e de solos combinados com Sistemas de Informações Geográficas e árvores de decisão no intuito de descrever, classificar e compartimentar a bacia do rio Itu.

As formas de relevo, as litologias e os solos constituem o substrato físico sobre o qual se desenvolvem as atividades humanas e dessa forma, trabalhos de zoneamentos que determinam unidades homogêneas são fundamentais para entendimento dos processos geomorfológicos e como as ações humanas podem interferir no meio.

A bacia hidrográfica do Rio Itu (BHRI), localizada no oeste do Rio Grande do Sul (RS), se caracteriza pelo predomínio de áreas de campos, regionalmente conhecido como campanha, tradicionalmente 


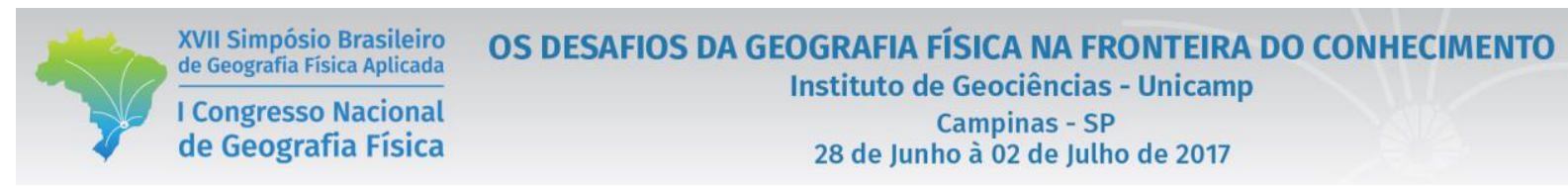

utilizado para a criação de gado de forma extensiva. Porém nas últimas décadas e mais constantemente nos últimos anos, observa-se significativas mudanças na dinâmica da região, onde os campos passam a ser explorados por culturas agrícolas e espécies exóticas em grandes áreas de florestamento.

O Rio Itu é afluente da margem direita do Rio Ibicuí, estendendo-se pelos municípios de São Francisco de Assis, Manuel Viana, Itaqui, Unistalda, Maçambará, São Borja e Santiago. Com uma área de 2.809,61 $\mathrm{km}^{2}$, esta bacia hidrográfica está inserida entre as coordenadas geográficas $54^{\circ} 52^{\prime} 20^{\prime}$ " a $55^{\circ} 53^{\prime} 15^{\prime \prime}$ de longitude oeste em relação ao meridiano de Greenwich, e $28^{\circ} 58^{\prime} 00^{\prime}$ ' a $29^{\circ} 24^{\prime} 40^{\prime}$ de latitude sul em relação à linha do Equador (Figura 01).

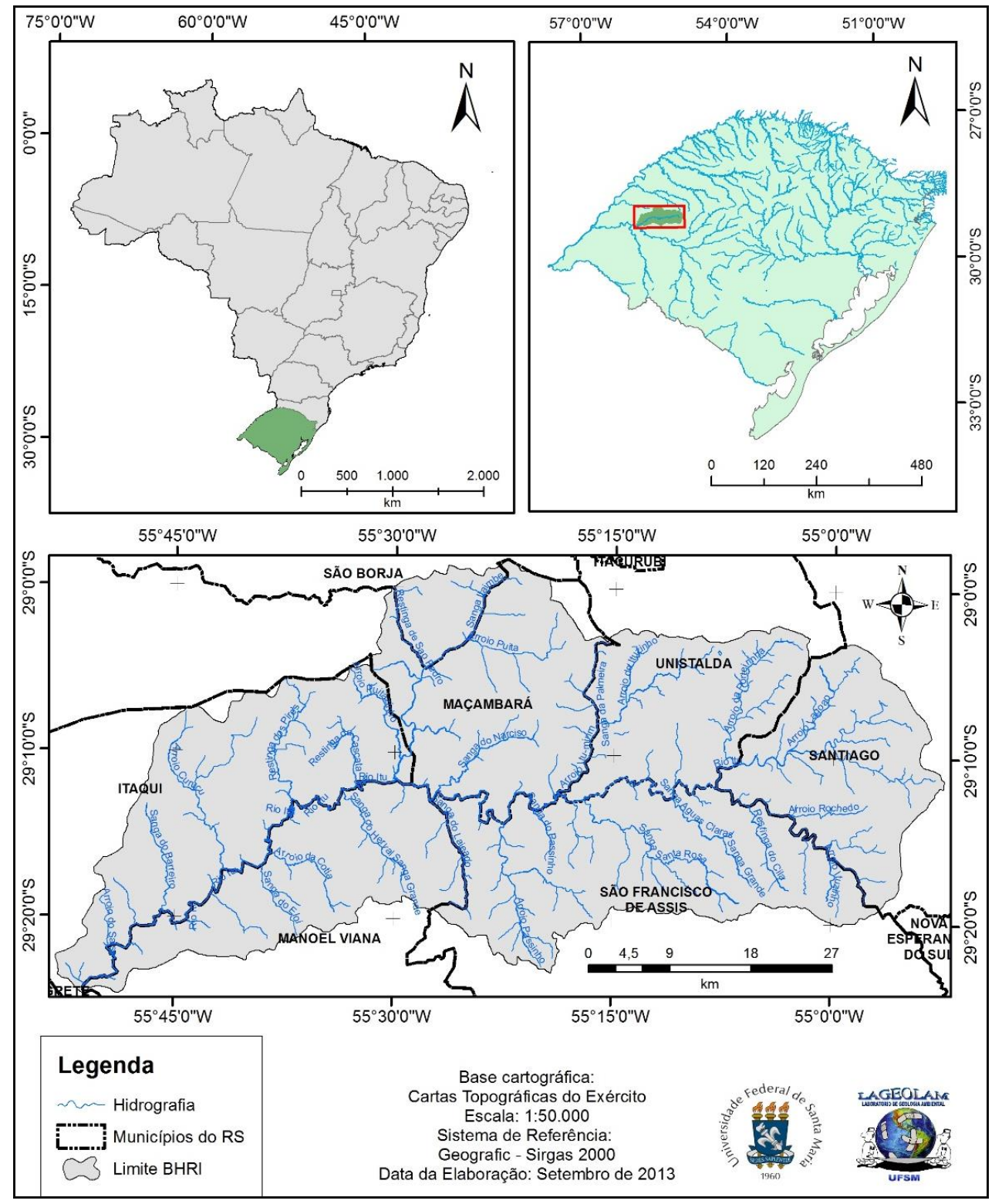

Figura 1 - Localização da bacia hidrográfica do Rio Itu, no estado do Rio Grande do Sul 


\section{Materiais e Métodos}

A base digital de elevação utilizada foram os dados do Radar SRTM (Shuttle Radar Topography Mission) disponíveis no site do Serviço Geológico Americano com resolução espacial de 3 Arc second (aproximadamente 90 metros) (KRETSCH, 2000). A base litológica e de solos, foi utilizado de (TRENTIN, 2011), que é um levantamento realizado com base em (WILDNER et al., 2006) e (STRECK et al., 2008) e, em trabalhos de campo com descrições e análises de amostras de rocha e solos

A definição das unidades fisiográficas da bacia hidrográfica do rio Itu, levou em consideração quatro temas básicos: altitude; declividade; litologia e solos. Quanto aos parâmetros de altitude, os mesmos foram classificados em duas classes, utilizando-se como limite das classes, a média da altitude da bacia hidrográfica (186 metros), sendo que a mesma possui uma amplitude altimétrica de 382 metros, com a altitude máxima 444 metros e a altitude mínima de 62 metros.

Os dados de declividade foram classificados em duas unidade, tendo como limite das classes a declividade de 15\%, limite este, utilizado pelo IPT (1981) bem como nos trabalhos desenvolvidos no Laboratório de Geologia Ambiental (TRENTIN, ROMARIO; SANTOS, LEONARDO JOSÉ CORDEIRO; ROBAINA, 2012); (TRENTIN, 2011) (ROBAINA et al., 2010), entre outros, para definição de classes de relevo, visto que este limite é o máximo possível para aplicação de maquinário agrícola, em construções necessita-se de cortes e aterros planejados.

Para os parâmetros de litologia, os dados foram classificados em duas classes. A primeira compreende os depósitos e sedimentos recentes e as rochas sedimentares, sendo estas definidas como arenitos fluviais da Formação Guará (SCHERER; FACCINI; LAVINA, 2002) e da Formação Botucatu (GONZAGA DE CAMPOS, 1889). Já a segunda classe compreende as rochas vulcânicas, sendo incorporados diversos derrames de rochas da Formação Serra Geral (WILDNER et al., 2006) que se encontra na área de estudo.

Os dados de solos são procedentes do mapa de solos simplificado elaborado por Trentin (2011), que possui como base de elaboração o mapa de solos do estado do Rio Grande do Sul (STRECK et al., 2008) e em descrições e análises de amostras de solo em campo e laboratoriais. Os solos foram agrupados em três classes sendo estas definidas como solos hidromórficos, solos rasos e solos profundos. Na classe de solos hidromórficos foram incorporados os Planossolos e os Plintossolos que ocorrem exclusivamente associados aos cursos d'água. Na classe dos solos rasos foram incorporados os Neossolos, os Cambissolos e as associações de Cambissolos e Neossolos. Na classe dos solos profundos foram incorporados os Nitossolos, os Argissolos, os Latossolos e os Neossolos quartzarênicos. 


\section{OS DESAFIOS DA GEOGRAFIA FÍSICA NA FRONTEIRA DO CONHECIMENTO \\ Instituto de Geociências - Unicamp \\ Campinas - SP \\ 28 de Junho à 02 de Julho de 2017}

Após a definição e agrupamento dos quatro temas centrais (altitude, declividade, litologia e solos) a serem utilizados na definição das unidades fisiográficas, as camadas, em modelo raster, foram cruzadas em ambiente SIG, com uso da ferramenta "combine", sendo definidas 24 unidades fisiográficas, conforme pode-se observar no fluxograma da figura 2.

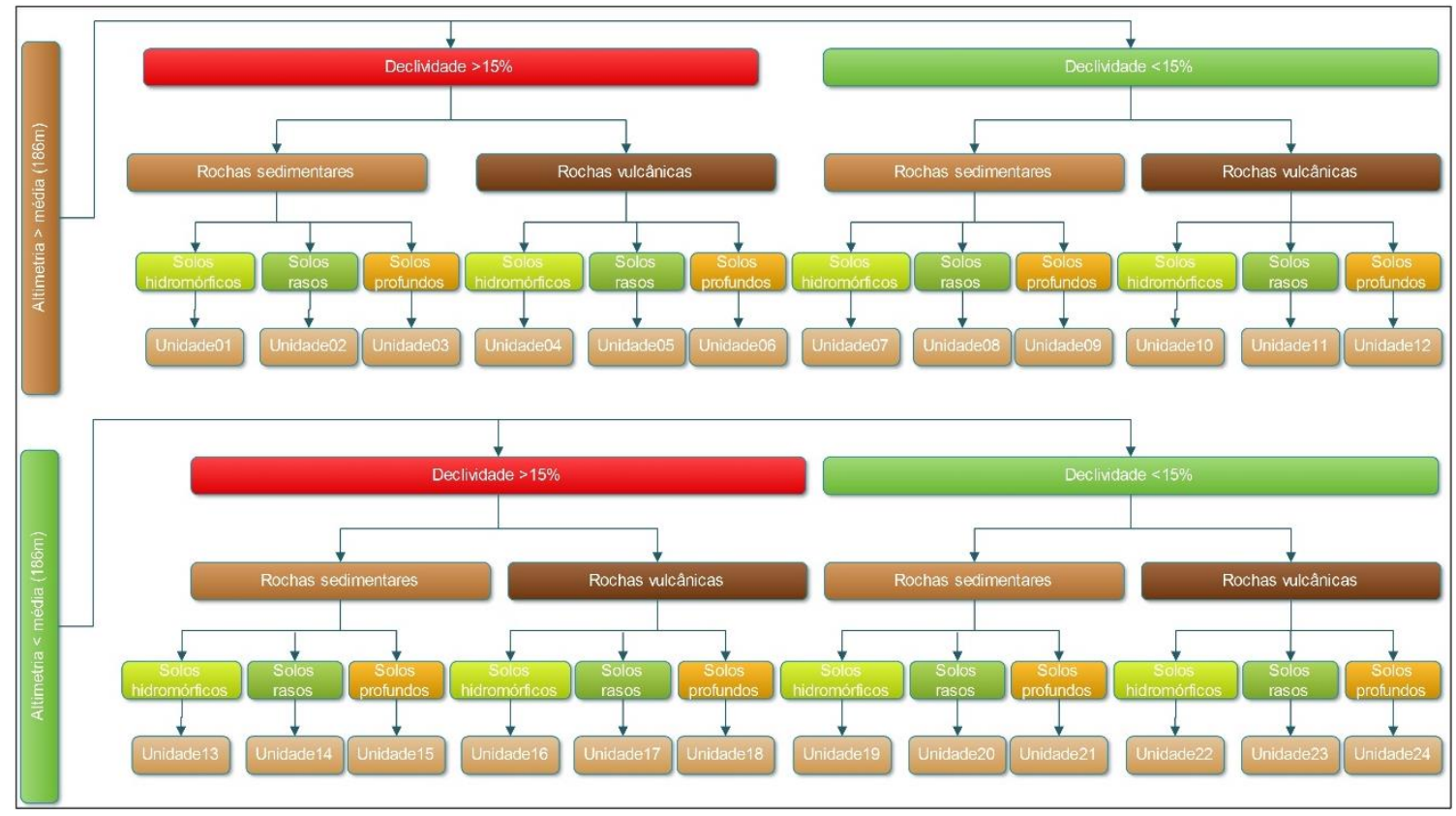

Figura 2 - Fluxograma do cruzamento dos parâmetros para a definição das unidades fisiográficas

As unidades 01, 02, 04, 07, 10, 13, 15, 16 e 18, não apresentam representatividade em área ocupada na bacia hidrográfica e/ou não apresentam continuidade na representação espacial, sendo desta forma agrupadas às unidades com características semelhantes.

Através da análise estatística e da distribuição espacial de cada uma das classes definidas, as mesmas foram reagrupadas para um total de 15 unidades, ou seja, as unidades que apresentaram menos que $0,5 \%$ da área total da bacia hidrográficas, ou que não apresentavam continuidade espacial de ocorrência, foram incluídas nas classes próximas e/ou representativas a um dos atributos de análise. Algumas classes, nem se quer apresentaram ocorrência, devido aos cruzamentos das variáveis, como é o caso da unidade 01, que representaria solos hidromórficos em declividades superiores à $15 \%$, o que naturalmente é inviável à ocorrência desta unidade. 


\section{COMPARTIMENTAÇÃO FISOGRÁFICA}

A figura 3 apresenta a distribuição espacial das unidades fisiográficas definidas para a bacia hidrográfica do Rio Itu. São apresentadas e especializadas 15 unidades que representam as características dos cruzamentos das informações das altitudes, declividade; litologia e solos, descritas e contextualizadas a seguir.

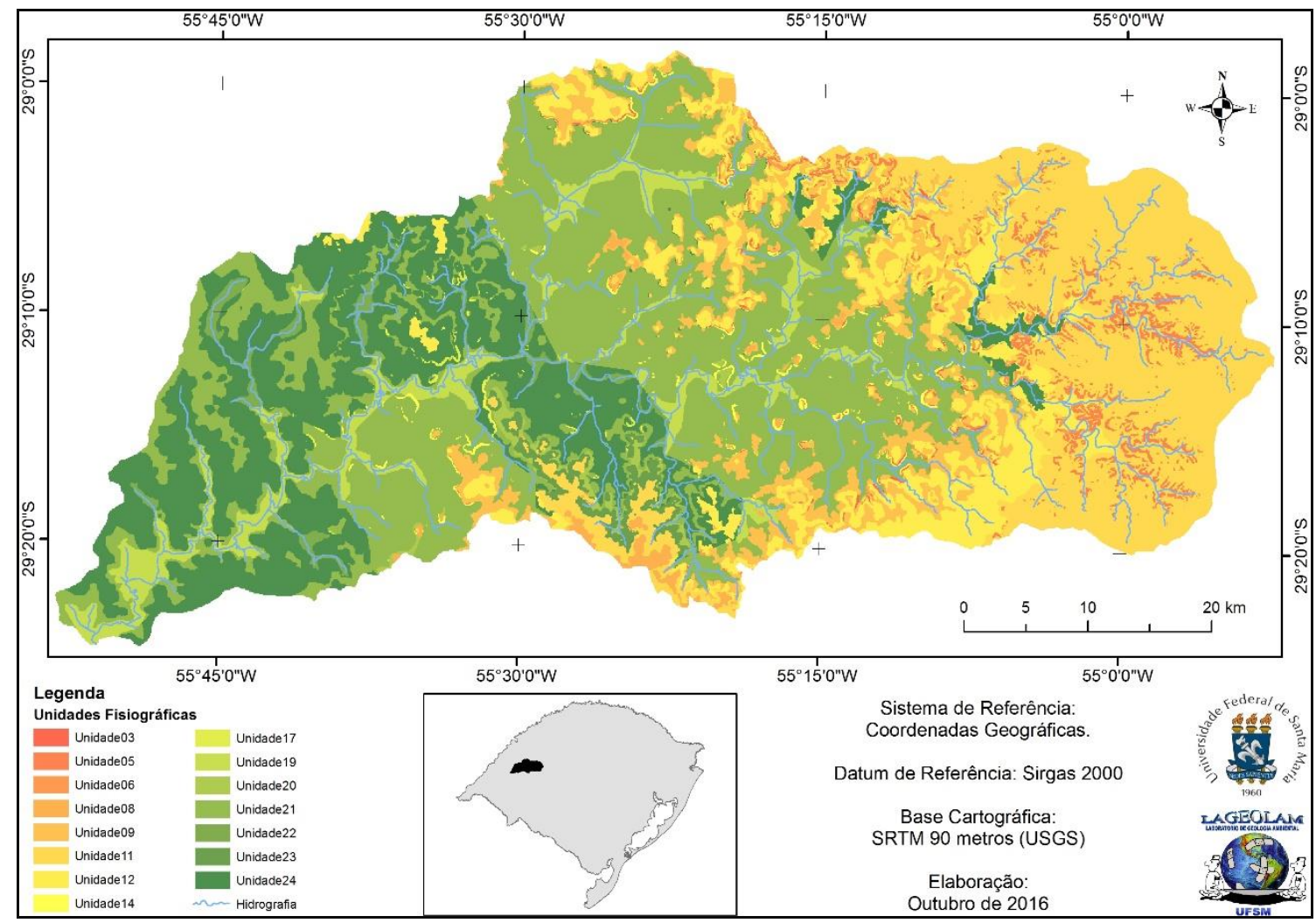

Figura 03 - Distribuição espacial das unidades fisiográficas da bacia hidrográfica do Rio Itu

Unidade de escarpas em Arenito no alto curso (03): Esta unidade ocorre em uma área de 10,13 km², que corresponde a $0,36 \%$ do total da bacia. Apesar de pouco expressiva, ocorre concentrada em pequenas faixas, representando depósitos de encosta de altitude, com declives superiores a 15\% sobre substrato de arenitos. Espacialmente distribui-se por uma faixa norte-sul no terço superior da bacia hidrográfica associado aos morros e morrotes de arenito. A figura 04 mostra a distribuição desta unidade ao longo da bacia.

Unidade de escarpas vulcânicas no alto curso (05): A unidade 05 ocupa uma área de 52,83 $\mathrm{km}^{2}$ correspondendo a 1,89\% do total, com distribuição apresentada na figura 04. Representam áreas de encostas inclinadas seguindo os vales encaixados das drenagens do alto curso, com solos rasos sobre rocha 


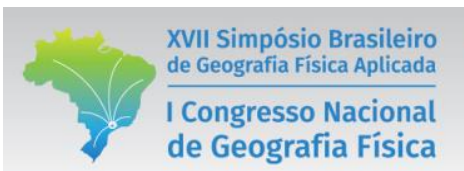

\section{OS DESAFIOS DA GEOGRAFIA FÍSICA NA FRONTEIRA DO CONHECIMENTO \\ Instituto de Geociências - Unicamp \\ Campinas - SP \\ 28 de Junho à 02 de Julho de 2017}

vulcânica. Espacialmente esta unidade estende-se no alto curso da bacia hidrográfica, associado à porção do Rebordo do Planalto.

Unidade de Patamares entre escarpas (06): Representam porções pouco significativas com área de 18,34 $\mathrm{km}^{2}$, correspondendo $0,65 \%$ do total da bacia. Está representada por relevo, relativamente, inclinado, mas que formam pequenos patamares com solos bem desenvolvidos, especialmente em áreas de contato entre derrames. Espacialmente ocupa uma faixa norte sul, marcando a transição do médio para o alto curso (figura 04).

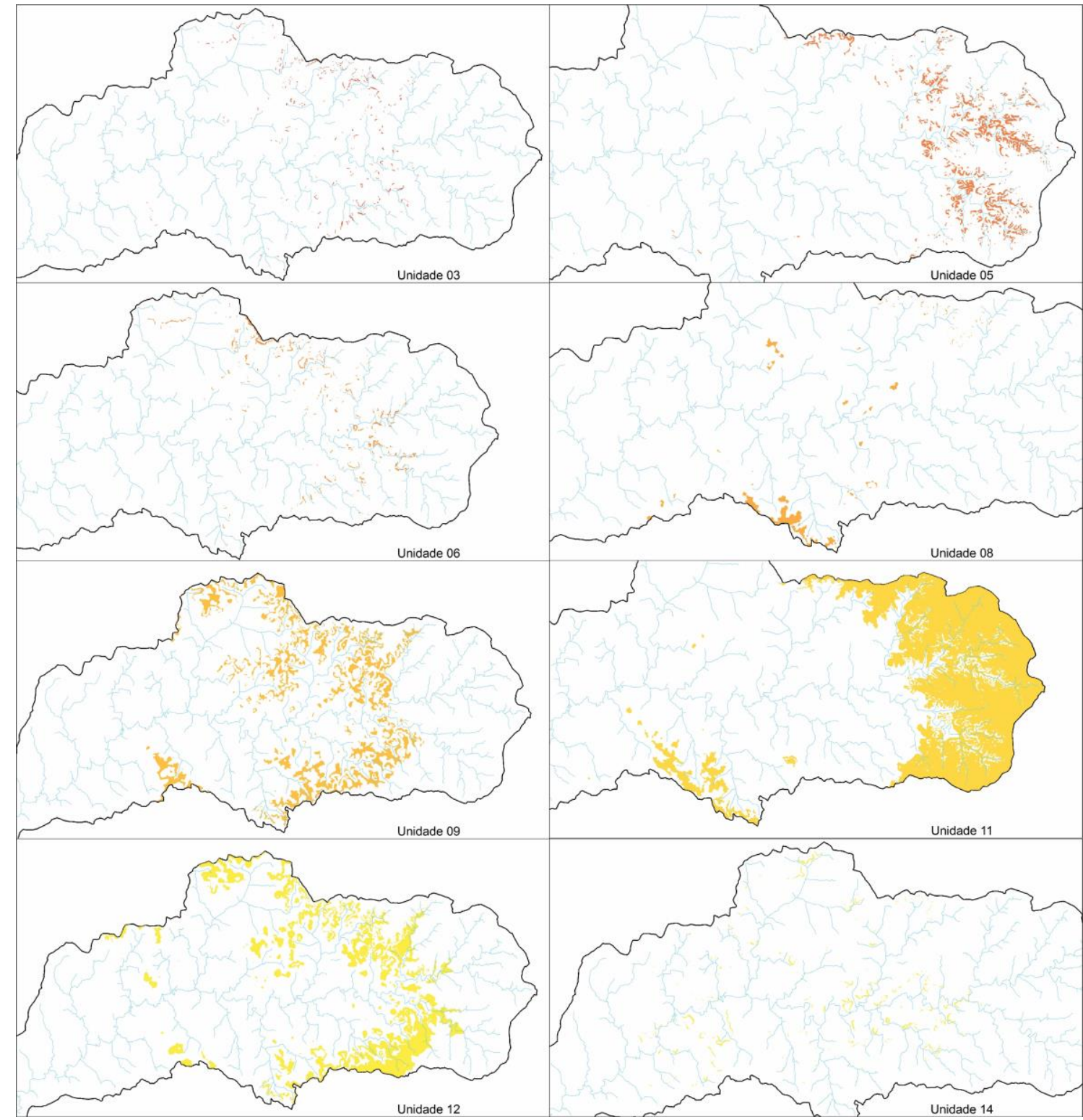

Figura 04 - Distribuição espacial das unidades fisiográficas 03, 05, 06, 08, 09,11 12 e 14 isoladamente na bacia hidrográfica do Rio Itu 
Unidade de Morros e Morrotes em Arenitos (08): Formam compartimentos isolados no médio curso associado a elevações de arenitos resistentes com área de $19,02 \mathrm{~km}^{2}$, correspondendo a $0,68 \%$ da bacia. Ocorrem com maior importância nas nascentes do arroio Passinho e sanga do Lajeado associadas a um relevo de morros e morrotes de arenitos com solos rasos associados com blocos e matacões. Espacialmente ocupa a porção central da bacia hidrográfica, associada aos divisores d'água (Figura 04).

Unidade de colinas arenosas (09): Correspondem a áreas onduladas, com substrato de rocha arenítica e solos profundos arenosos que marcam a passagem das áreas do Planalto para a Depressão periférica. Ocorrem em uma área de 200,3 $\mathrm{km}^{2}$, correspondendo a 7,15\% da bacia. Espacialmente distribui-se pela porção central da bacia hidrográfica (Figura 04).

Unidade de colinas em vulcânicas do alto curso (11): Esta unidade ocorre na porção leste da bacia, alto curso, e em menor concentração na porção centro sul (figura 04), com área total de 504,83 km², representando $18,03 \%$ da área total da bacia. Constituem as porções associadas a um relevo ondulado com substrato de rochas vulcânicas. Os solos são rasos devido a maior resistência e a estrutura em fraturas horizontais das rochas do substrato. Espacialmente esta unidade ocupa a terceira maior área da bacia hidrográfica.

Unidade de colinas entre Morros (12): Unidade formada por um relevo ondulado representando áreas de colinas entre morros, com área de $271,89 \mathrm{~km}^{2}$, representando $9,71 \%$ da bacia. Os solos são bem desenvolvidos sobre substrato de rochas vulcânicas devido a maior infiltração favorecendo os processos de pedogênese. Espacialmente, estende-se pela porção central da bacia (figura 04) representando a quarta maior área da bacia.

Unidade de escarpa em arenitos de baixo-médio curso (14): Esta unidade representa as áreas de encostas inclinadas que ocorrem em elevações (morros e morrotes) de arenitos. Formam uma área restrita na bacia com $18,11 \mathrm{~km}^{2}$ que corresponde a $0,65 \%$ Os solos são rasos devido à resistência da litologia arenítica e a inclinação da encosta. Espacialmente ocorrem no médio e baixo curso da bacia (Figura 04).

Unidade de escarpas em vulcânicas no baixo curso (17): Unidade caracterizada por porções de encosta sobre um substrato de rochas vulcânicas, com área de $6 \mathrm{~km}^{2}$, que representa $0,21 \%$ da bacia. Marcam as encostas dos morros testemunhos formados no recuo erosivo do Planalto. Espacialmente ocorrem em pequenas áreas junto ao baixo curso (figura 05).

Unidade de planície de inundação (19): Unidade associada a planície de inundação do rio Itu e de seus afluentes principais com área de $157,09 \mathrm{~km}^{2}$, representando 5,61\% da bacia. Constituem áreas com baixa 


$\begin{aligned} & \text { XVII Simpósio Brasileiro } \\ & \text { de Geografia Fisica Aplicada }\end{aligned}$
$\begin{aligned} & \text { ICongresso Nacional } \\ & \text { de Geografia Física }\end{aligned}$

inclinação formadas por depósitos dos rios e solos hidromórficos. Espacialmente ocupam áreas do baixo e médio curso (figura 05), representando a quinta maior área da bacia hidrográfica.

Unidade de Cornijas areníticas (20): Esta unidade é pouco representativa, ocorrendo em área de 16,62 $\mathrm{km}^{2}$ com 0,59\% da bacia, mas é suma importância pois marca os degraus de rochas sedimentares resistentes com solos rasos que ocorre na meia encosta. Espacialmente ocorrem associados ao médio curso da bacia hidrográfica (figura 05).

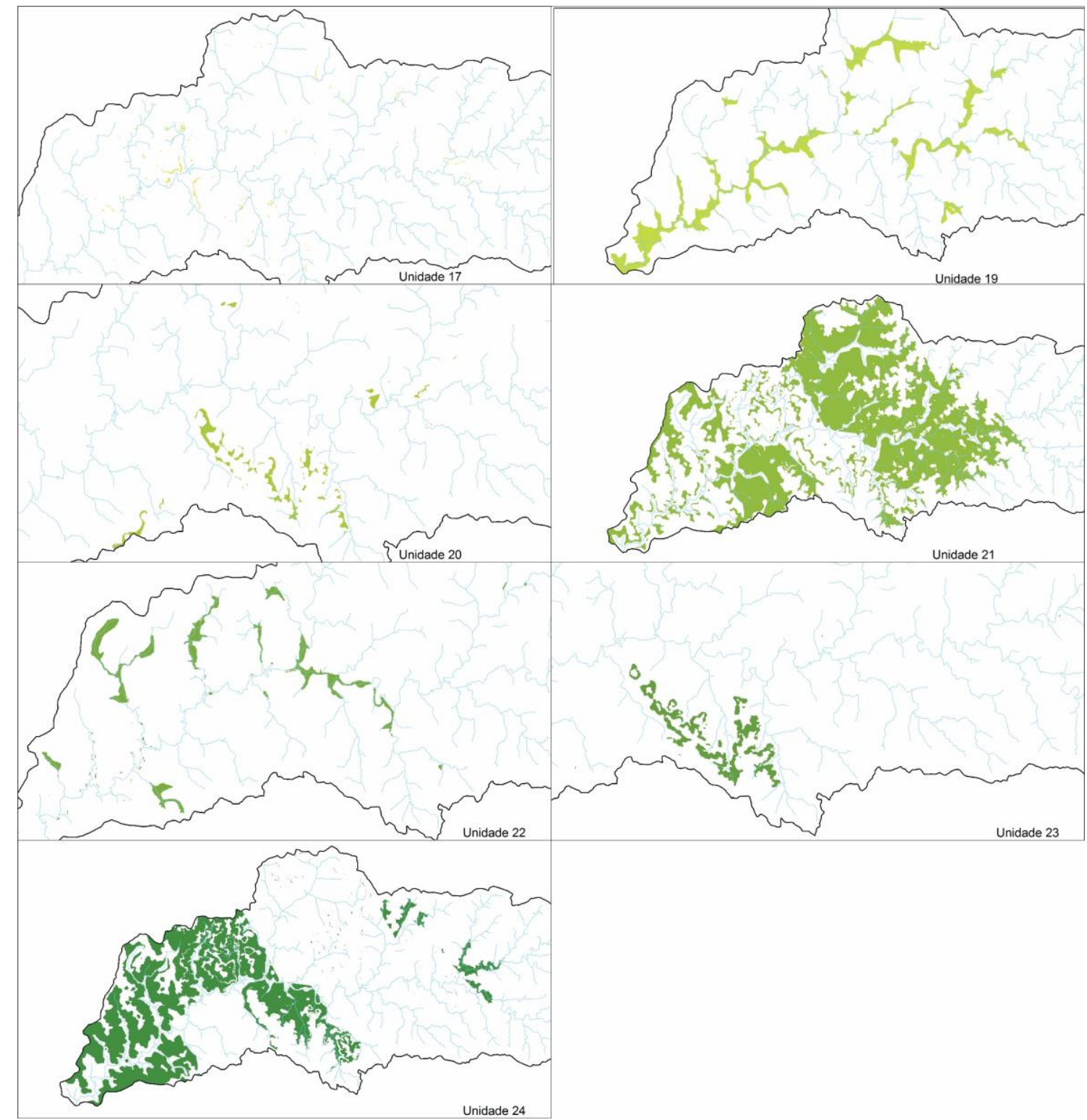

Figura 05 - Distribuição espacial das unidades fisiográficas 17, 19, 20, 21, 22, 23 e 24 isoladamente na bacia hidrográfica do Rio Itu 
Unidade de colinas arenosas do médio-baixo curso (21): Unidade importante em área, com 915,49 km² que corresponde a 32,69\% da bacia. Constituem o relevo ondulado de colinas sobre um substrato de arenitos. Os solos nessa área são profundos e arenosos. Espacialmente é a maior área da bacia hidrográfica e ocorre concentrada em grandes áreas do médio e baixo curso (Figura 05).

Unidade planície de inundação sobre vulcânicas (22): Unidade de solos hidromórficos com substrato de rocha vulcânica, ocorrendo com área de 44,47 km², que corresponde a 1,59\%, associada a planície de inundação do rio Itu e de afluentes. Espacialmente ocorrem no baixo curso da bacia hidrográfica (figura $05)$.

Unidade de colinas vulcânicas com solos rasos (23): Unidade com pequena área na bacia com $28,45 \mathrm{~km}^{2}$ (1,02\% da área total), mas concentrado nas sub bacias do arroio Passinho, sanga do Lajeado e sanga do Herval, afluente do médio curso do rio Itu (figura 05). Forma um relevo ondulado de colinas sobre rocha vulcânica com solos rasos.

Unidade de colinas vulcânicas com solos profundos (24): Unidade predominante no baixo curso (figura 05), com área de $53,89 \mathrm{~km}^{2}$ que representa $19,17 \%$ da bacia. A unidade forma um relevo ondulado sobre um substrato de rochas vulcânicas e com predomínio de solos bem desenvolvidos. Espacialmente ocupa a segunda maior área da bacia hidrográfica.

\section{Considerações Finais}

A definição de unidade fisiográficas possibilitam a compreensão das características físicas de uma determinada área de estudo, através da distribuição espacial das propriedades específicas encontradas em cada unidade. Assim sendo, foi possível definir espacialmente diferentes unidades fisiográficas através dos atributos físicos específicos.

O cruzamento automático dos temas agiliza o processamentos das informações e possibilita a determinação precisa das unidades com as características definidas no cruzamento, porém condiciona a formação de unidades que espacialmente ou tematicamente não são possíveis de serem representadas, como é o caso de unidade com solos hidromórficos em declividades acima de 15\%, o que, requer do interprete, o bom senso de intervenções junto à determinadas áreas, conforme as especificidades de cada área de estudo.

Na bacia hidrográfica do Rio Itu, foi realizado o cruzamento das variáveis altitude, declividade, litologia e solos, de forma e diferenciar 24 unidades fisiográficas. Após análise da representação espacial algumas 
unidades foram reagrupadas às unidades com características semelhantes o que condicionou a delimitação de 15 unidades fisiográficas representativas.

Das 15 unidades fisiográficas seis são grandes unidades espaciais que representam as características predominantes na bacia hidrográficas, porém as nove demais unidades, apesar de ocuparem pequenas áreas, representam situações especificas na área de estudo.

\section{Bibliografia}

CARRARO, C. C.; LIU, C. C.; YAMAGATA, S. K. Interpretação geológica da região do Alto e Médio São Francisco baseada nas imagens MSS do ERTS-1. INPE TPT, v. 790, p. 1-115, 1975.

CHORLEY, R. J.; SCHUMM, S. A.; SUGDEN, D. E. Geomorphology. Geomorphology., 1984.

CHRISTOFOLETTI, A. Modelagem de Sistemas Ambientais. São Paulo: Editora Edgard Blücher, 1999.

CUNHA, S. B.; GUERRA, A. Geomorfologia e Meio Ambiente. 3. ed. Rio de Janeiro: Bertrand Brasil, 1996.

FREITAS, M. W. D.; CUNHA, S. B. Geossistemas e Gestão Ambiental na Bacia Hidrográfica do Rio São JoãoRJ. Anais do 5o Simpósio de Nacional de Geomorfologia e 1o Encontro Sul-Americano de Geomorfologia. Anais...Santa Maria: 2004

GONZAGA DE CAMPOS, L. F. Secção geológica. São Paulo: [s.n.].

KRETSCH, J. L. Shuttle radar topography mission overview. Proceedings - Applied Imagery Pattern Recognition Workshop. Anais...Institute of Electrical and Electronics Engineers Inc., 2000

MACIEL FILHO, C. L.; SARTORI, P. L. P. Aspectos Estruturais da Região de São Francisco de Assis, RS. Ciência e Natura, v. 1, p. 53-65, 1979.

MILANI, E. J. Geodinâmica Fanerozóica do Gondwana Sul-Ocidental e a Evolução Geológica da Bacia do Paraná. In: HOLZ, M.; DE ROS, L. V. (Eds.). Geologia do Rio Grande do Sul. Porto Alegre: CIGO/UFRGS, 2002. p. 275302.

PIRES, J. L. O planejamento das atividades de mineração para a área conurbada de Florianópolis. [s.l.] Dissertação (Mestrado em Engenharia Civil) -Curso de Pós-Graduação em Engenharia Civil, Universidade Federal de Santa Catarina, 2000. 


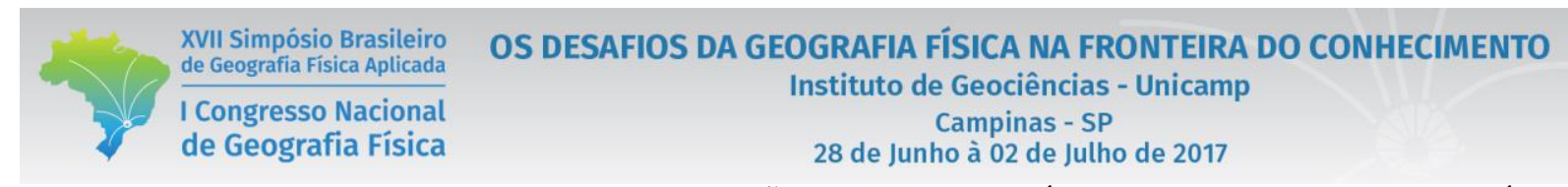

ROBAINA, L. E. DE S. et al. COMPARTIMENTAÇÃO GEOMORFOLÓGICA DA BACIA HIDROGRÁFICA DO IBICUÍ, RIO GRANDE DO SUL, BRASIL: PROPOSTA DE CLASSIFICAÇÃO. Revista Brasileira de Geomorfologia, v. 11, n. 2, p. 11-23, 2010.

SCHERER, C. M. S.; FACCINI, U. F.; LAVINA, E. Arcabouço Estratigráfico do Mesozóico da Bacia do Paraná. In: HOLZ, M.; DE ROS, L. V.; L.V. (Eds.). Geologia do Rio Grande do Sul. Porto Alegre: CIGO/UFRGS, 2002. p. $335-354$.

SECRETARIA DA COORDENAÇÃO E PLANEJAMENTO. Atlas Socioeconômico do Rio Grande do Sul. 2 . ed. Porto Alegre: SCP, 2002.

STRECK, E. V. et al. Solos do Rio Grande do Sul. 2. ed. Porto Alegre: Emater/RS, 2008.

SUERTEGARAY, D. M. A. O Rio Grande do Sul descobre seus “desertos”. Ciência \& Ambiente, v. 1, n. 1, p. 34$52,1995$.

SUERTEGARAY, D. M. A.; GUASSELI, L. A.; VERDUM, R. Atlas da arenização: Sudoeste do Rio Grande do Sul. Porto Alegre: Secretaria da Coordenação e Planejamento do Rio Grande do Sul, 2001.

TRENTIN, ROMARIO; SANTOS, LEONARDO JOSÉ CORDEIRO; ROBAINA, L. E. DE S. Compartimentação geomorfológica da bacia hidrográfica do rio Itu - Oeste do Rio Grande do Sul - Brasil. Sociedade \& Natureza, v. 24, n. 1, p. 127-142, 2012.

TRENTIN, R. Mapeamento geomorfológico e caracterização geoambiental da bacia hidrográfica do Rio Itu oeste do Rio Grande do Sul - Brasil. [s.1.] Universidade Federal do Paraná, 2011.

TROPPMAIR, H. Biogeografia e Meio Ambiente. 6. ed. Rio Claro: [s.n.].

VIDAL-TORRADO, P.; LEPSCH, I. F.; CASTRO, S. S. Conceitos e aplicações das relações pedologiageomorfologia em regiões tropicais úmidas. In: Tópicos em Ciência do Solo. Viçosa: Sociedade Brasileira de Ciência do Solo, 2005. p. 145-192.

WILDNER, W. et al. Mapa Geológico do Estado do Rio Grande do Sul - Escala 1:750000Porto Alegre CPRM, Serviço Geológico do Brasil, 2006.

ZUQUETTE, L. V. Importância do mapeamento geotécnico no uso e ocupação do meio físico: fundamentos e guia para elaboração. [s.1] Escola de Engenharia de São Carlos, Universidade de São Paulo, São Carlos, 1993. 